\section{Pacific Northwest}

National Laboratory

Operated by Battelle for the

U.S. Department of Energy

\title{
Estimating Worker Risk Levels Using Accident/Incident Data
}

\author{
JL Kenoyer \\ RD Stenner \\ RI Scherpelz \\ WB Andrews \\ RD Aaberg
}

September 2000

Prepared for the U.S. Department of Energy

under Contract DE-AC06-76RL01830 


\section{DISCLAIMER}

This report was prepared as an account of work sponsored by an agency of the United States Government. Neither the United States Government nor any agency thereof, nor Battelle Memorial Institute, nor any of their employees, makes any warranty, express or implied, or assumes any legal liability or responsibility for the accuracy, completeness, or usefulness of any information, apparatus, product, or process disclosed, or represents that its use would not infringe privately owned rights. Reference herein to any specific commercial product, process, or service by trade name, trademark, manufacturer, or otherwise does not necessarily constitute or imply its endorsement, recommendation, or favoring by the United States Government or any agency thereof, or Battelle Memorial Institute. The views and opinions of authors expressed herein do not necessarily state or reflect those of the United States Government or any agency thereof.

\section{PACIFIC NORTHWEST NATIONAL LABORATORY operated by \\ BATTELLE \\ for the \\ UNITED STATES DEPARTMENT OF ENERGY \\ under Contract DE-AC06-76RL01830}

Printed in the United States of America

Available to DOE and DOE contractors from the

Office of Scientific and Technical Information,

P.O. Box 62, Oak Ridge, TN 37831-0062;

ph: (865) 576-8401

fax: (865) 576-5728

email: reports@adonis.osti.gov

\footnotetext{
Available to the public from the National Technical Information Service, U.S. Department of Commerce, 5285 Port Royal Rd., Springfield, VA 22161 ph: (800) 553-6847 fax: (703) 605-6900

email: orders@ntis.fedworld.gov

online ordering: http://www.ntis.gov!ordering.htm
} 
PNNL-13338

\title{
Estimating Worker Risk Levels Using Accident/Incident Data
}

\author{
J. L. Kenoyer \\ R. I. Scherpelz \\ R. D. Stenner \\ R. D. Aaberg \\ W. B. Andrews
}

September 2000

Prepared for

the U.S. Department of Energy

under Contract DE-AC06-76RLO 1830

Pacific Northwest National Laboratory

Richland, Washington 99352 


\section{Summary}

The purpose of the work described in this report was to identify methods that are currently being used in the Department of Energy (DOE) complex to identify and control hazards/risks in the workplace, evaluate them in terms of their effectiveness in reducing risk to the workers, and develop a preliminary method that could be used to predict the relative risks to workers performing proposed tasks using some of the current methodology. It is recognized that some of the methods discussed in this report on the evaluation of workplace safety levels or the reduction of risks in the workplace do not apply to lower-risk work environments. They are more applicable to high-risk tasks, projects, or programs.

This report describes some of the lagging performance indicators (i.e., safety metrics) that are currently being used to track relative levels of workplace safety in the DOE complex, how these fit into an Integrated Safety Management (ISM) system, some strengths and weaknesses of using a statistically based set of indicators, and methods to evaluate them. Also discussed are methods used to reduce risk to the workers and some of the techniques that appear to be working in establishing a process of continuous improvement. The results of these methods will be used in future work to determine modifying factors for a more complex model.

The preliminary method to predict the relative risk level to workers during an extended future time period is based on a currently used performance indicator that uses several factors tracked in the Computerized Accidentllncident Reporting System (CAIRS). The relative risks for workers in a sample (but real) facility on the Hanford Site are estimated for a time period of 20 years and are based on workforce predictions. This is the first step in developing a more complex model that will incorporate other modifying factors related to the workers, work environment, and status of the ISM system to adjust the preliminary prediction. 



\section{Acknowledgments}

A special acknowledgment and thanks go to AI Young and Mark Bollinger of the Department of Energy - Center for Risk Excellence (CRE), and the CRE Board, for identifying the need for a methodology to estimate worker risk levels using accident/incident data. They also provided funding and guidance for the development of this methodology.

The authors also wish to acknowledge and thank Roby Enge (PNNL ES\&H Manager) and Hans Vogel (PNNL 1OPS Manager) for their insight and suggestions on worker health and safety in relation to ISM.

The authors also wish to acknowledge and thank Jim Weber for his thorough technical editing and ability to combine input from several staff into one cohesive report. 



\section{Contents}

$\begin{array}{lr}\text { Sununary } & 111\end{array}$

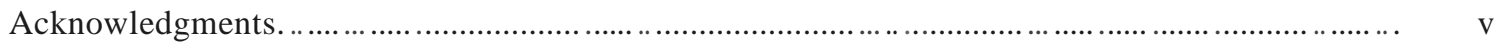

$\begin{array}{llr}1.0 \text { Introduction } & 1.1\end{array}$

$\begin{array}{lll}1.1 & \text { Risk Defined.. } & 1.1\end{array}$

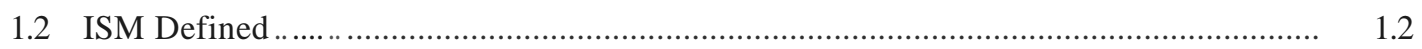

$\begin{array}{llr}1.3 & \text { The Current Situation } & 1.3\end{array}$

$\begin{array}{llr}2.0 \text { Methods } & 2.1\end{array}$

$\begin{array}{ll}2.1 \text { Enhancement ofISM Systems } & 2.1\end{array}$

2.1.1 Incorporation of Behavior-Based Safety Principles $\quad 2.1$

2.1.2 Development of Relative Risk Factors............................................... 2.4

2.1.3 Use of Electronic Standards-Based Management Systems 2.4

$\begin{array}{lll}\text { 2.1.4 Use of Performance Indicators } & 2.5\end{array}$

$\begin{array}{lll}2.2 & \text { Performance Indicators } & 2.5\end{array}$

2.2.1 Relative Risk Comparison for Worker Injury/Illness.................................. 2.7

$\begin{array}{llr}3.0 & \text { Results } & 3.1\end{array}$

3.1 Calculation of Relative Physical Hazard Levels 3.1

3.2 Calculation of Predicted Levels of Relative Risks (RPHI) versus Time...................... 3.3

$\begin{array}{llr}4.0 & \text { Conclusions } & 4.1\end{array}$

$\begin{array}{llr}5.0 & \text { References } & 5 . \mathrm{I}\end{array}$ 


\section{Figures}

$\begin{array}{lr}\text { Severity Rate vs. Time } & 1.5\end{array}$

2 Injury and Illness Cases per 200,000 Hours vs. Time.

1.5

3 Relative Physical Hazard Index as a Function of Time - Simple Model-Based on

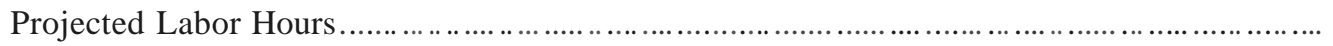

\section{Tables}

Example Relative Physical Hazard Levels

3.1

2 Relative Physical Hazard Level for the Example Site Program Operations

3.2

3 Annual Relative Physical Hazard Indices

3.4 


\subsection{Introduction}

The purpose of the work described in this report was to identify methods that are currently being used in the Department of Energy (DOE) complex to identify and control hazards/risks in the workplace, evaluate them in terms of their effectiveness in reducing risk to the workers, and develop a preliminary method that could be used to predict the relative risks to workers performing proposed tasks using some of the current methodology. The methods identified and discussed apply more to high-risk workplace environments than low-level risk tasks, projects, or programs.

As part of the process of developing the simple model, a secondary purpose was established. This was to create a road map that others could use that identified the steps required to obtain the data from the statistical database, other tasks that needed to be performed to obtain useful data (i.e., other groups or people to talk to, to determine factors such as labor hours, contractors and job types), and other factors that needed to be known to evaluate and interpret the results.

Although the DOE has been engaged in the cleanup of its former nuclear weapons sites for more than a decade, most of the actual labor involved in remediating these sites lies in the future. Within the next 30 years, DOE will remediate thousands of waste sites across the DOE complex. A major concern will be the protection of thousands of workers engaged in the remediation activities. Although there will always be risk to the worker in remediation activities, the goal of DOE and its contractors is to minimize the risk and to do whatever can be done to make the workplace as safe as possible.

DOE and contractor upper management support worker safety. All sites are safety-conscious, all sites are installing or upgrading their Integrated Safety Management (ISM) systems, and all sites have lessonslearned programs. As one of its goals, DOE has chosen a mode of "continuous improvement" and intends to establish an excellent safety record in remediation activities. Performance indicators (or safety metrics) have been developed to track and trend the relative safety envirorunent in the workplace. Data for these indictors are normally accumulated on a monthly basis and reported either monthly or quarterly. The statistics available from the Computerized Accident/Incident Reporting System (CAIRS) database show that there could have been a leveling off or a plateauing of some of the safety parameters in the past and suggest that it may be occurring again. Work currently is continuing to identify and/or establish leading performance indicators and interpretive methods. Thus, further advances can be made in the sites' levels of safety.

\subsection{Risk Defined}

In general terms, risk can be defined by the following equation:

$$
\text { risk }=\text { severity } \mathrm{x} \text { probability }
$$

where severity relates to the consequences or the impact of the effect ofa specific activity that could occur, and probability is the likelihood of a specific activity or an adverse effect occurring. The greater 
the potential consequences of an activity or the greater the probability of that activity occurring, then the greater the risk will be. Risk can also be described at the quantitative or qualitative expression of possible loss that considers both the probability that a hazard will cause harm and the consequences of that event. Hazard is the source of danger (e.g., material, energy source, and operation) with the potential to cause illness, injury, or death to personnel or damage to a facility or the environment (DOE 1997). Because of the abundance and consistency of past data, probabilities of potential future events can be estimated using models. The risk of an action is zero if the action is not performed; so, if no work is done, the risk to the worker goes away. However, it is not practical to avoid all worker activity-there is a job to be done. As a part of integrated safety management, levels of risks are identified and managed such that they can be minimized while performing the required work for a reasonable cost.

\subsection{ISM Defined}

The identification and control of risks and hazards are important parts of any effective ISM system. As part of this project, the methods llsed within different ISM systems to reduce risk were evaluated for their effectiveness. It is important to know where these methods are included in the core functions and guiding principles of ISM.

Integrated safety management works ES\&H requirements into the processes of planning and conducting work to effectively protect the workers, the public, and the environment. ISM involves customer expectations and requirements; institutional policies and procedures' standards of performance; roles, responsibilities, accountabilities, and authorities (R2A2s); operating procedures, work controls and delivery mechanisms; performance monitoring and improvement; and lessons learned.

Among the core functions and guiding principles that mark ISM are

- defining the work and how it is to be prioritized and accomplished

- identifying and analyzing the hazards associated with the work

- identifying and implementing the controls (including requirements) tailored to the work and hazards

- performing the work as authorized following confirmation of readiness

- assessing the effectiveness of the system and providing feedback of results to improve the process.(a)

(a) U.S. Department of Energy (DOE). 2000. Draft DOE Program and Project Management Manual. DOE M 413.X, Washington, D.C. 
The guiding principles of ISM include the following:

- Management is responsible.

- Roles and responsibilities must be clearly defined.

- Competence is commensurate with responsibilities.

- ES\&H priorities are balanced.

- ES\&H standards and requirements are identified.

- Controls are tailored to the work.

- Work authorization is in place prior to work initiation.

\subsection{The Current Situation}

In April 1997, the DOE Laboratory Directors' Environmental and Occupational/Public Health Standards Steering Group and the U.S. Air Force Annstrong Laboratory sponsored a workshop on the health and safety of workers in environmental restoration, decontamination, and demolition. The workshop identified eight issues of importance - ones that describe some of the current reasons why risk in the workplace is not zero and how the workplace can be made safer (Worker Risk Workshop Report 1997). These issues included:

- lack of real-time monitoring and site characterization abilities

- inadequate documentation and tracking of worker exposures

- inadequate exposure methods for assessing worker protection for non-radiological issues

- subcontracting and fixed-price contracts

- need for a better balance between worker, public, and environmental risks

- need for an appropriate balance in protecting workers from safety and health exposures

- exclusion of workers from decisions, and

- inadequate value placed on safety.

The deadline for implementing ISM at all sites by September 2000 is here (Richardson 2000). However, the maturation of this process will take place over the coming 3 to 5 years. This is the time to 
go from strategic development to mature operations with improved perfonnance. The evolutionary cycle of designing improved worker safety strategies will involve development, implementation, verification, behavioral impacts, and perfonnance results, followed by some demonstration of causal relationships. DOE expectations for ISM success will drive continuing major ES\&H cultural changes and provide opportunities for deployment of enhanced approaches. The DOE and its contractors have made strides in making the workplace a safer environment and the risks to the community minimal. Some current examples of success can be found at the Hanford Site and at Brookhaven National Laboratory (DOE 2000a).

The DOE does recognize that true excellence can be encouraged and guided but not standardized. Therefore, DOE initiated the DOE Voluntary Protection Program (DOE-VPP) to encourage and recognize excellence in occupational safety and health protection. This program closely parallels the Occupational Safety and Health Administration's Voluntary Protection Program (OSHA-VPP). The VPP, adopted by OSHA on July 2, 1982, has established the credibility of cooperative action among government, industry, and labor to achieve improvement in worker health and safety. DOE-VPP outlines areas where DOE contractors and subcontractors can go beyond compliance with DOE Orders and the OSHA standards. The program encourages the creative stretch for excellence through systematic approaches involving everyone in the contractor and subcontractor workforces at DOE sites. DOE-VPP emphasizes creative solutions through cooperative efforts by managers, employees, and DOE. DOE-VPP consists of three levels of recognition: Star, Merit, and Demonstration, with Star being the highest level of recognition. Four DOE sites have achieved "Star" status: Honeywell, Inc. Federal Manufacturing and Technologies in Kansas City, MO; Westinghouse Waste Isolation Pilot Plant (WIPP) in Carlsbad, NM; Weldon Spring Site Remedial Action Project (WSSRAP) in St. Charles, MO; and Wackenhut Services, Inc., Savannah River (WSI-SR), Aiken, SC.

Figure I shows the influence of identifying and acting upon a safety issue or several safety issues over a number of years. The perfonnance indicator shows the severity of safety incidents to have been lowered significantly through improved reactions to acute situations. However, though the risk has decreased, there are events happening even after the "fix" has been made to a problem.

Figure 2 represents 15 years of DOE-wide data showing the Total Recordable Cases (per 200,000 hours) versus time from the CAIRS database. The step function in the data could be an artifact from the Tiger Team influence, which spurred better reporting. The cause of the current steady decline is unknown. It may represent the slow backsliding of contractors slowly resuming business pre-Tiger Team. However, it may also reflect the closing or slowing down of production facilities or the fact that there are fewer DOE contractor employees and fewer activities, hence, less risk and fewer reportable accidents/incident cases.

Although risk levels appear to have stabilized, the potential for accidents, overexposures, contamination incidences, and releases still exists. The risk of doing any work will never be zero; however, we can strive for continuous improvement. The ideas presented here inject the concept of risk into the safety management system and evaluate methods that pursue continuous improvement. In the 


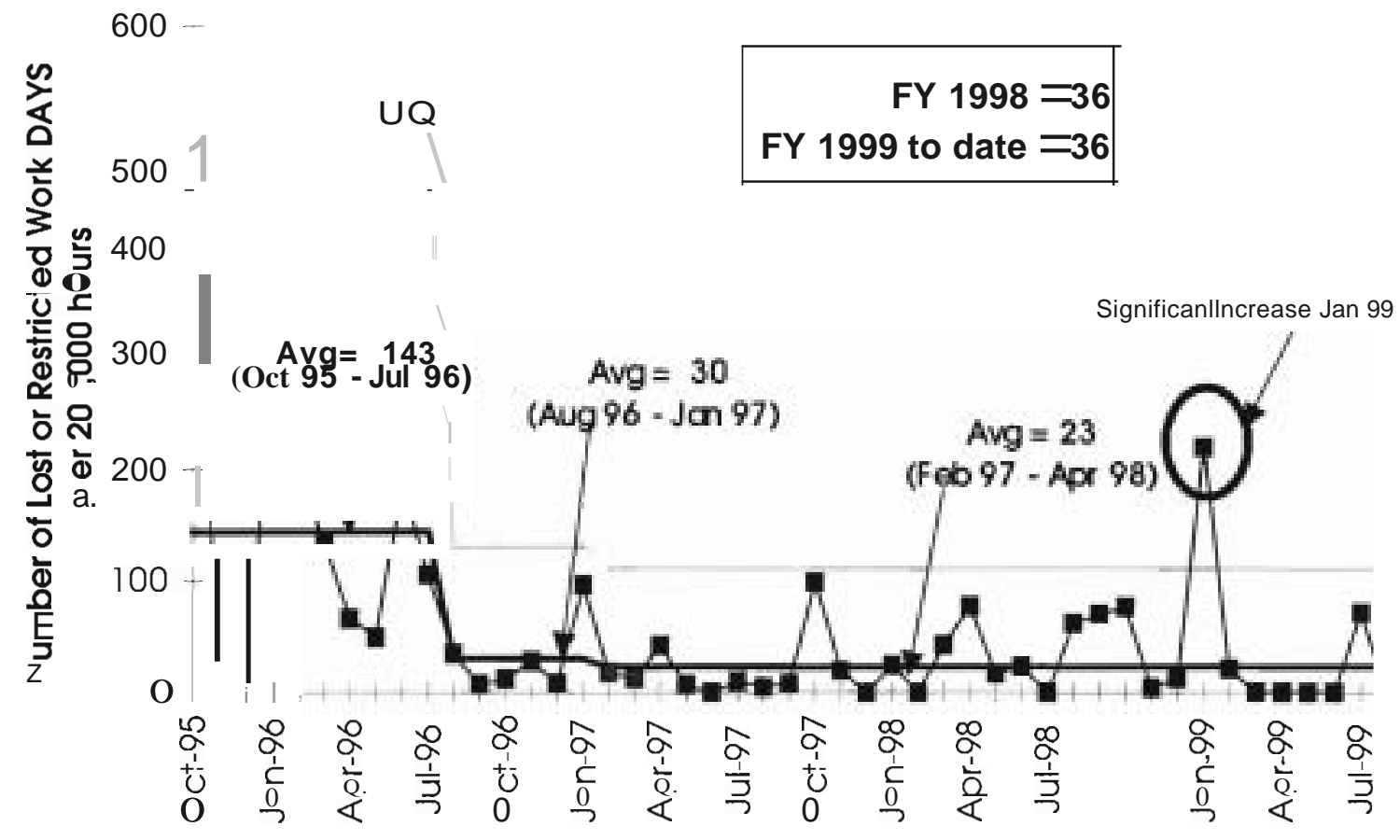

Figure 1. Severity Rate vs. Time

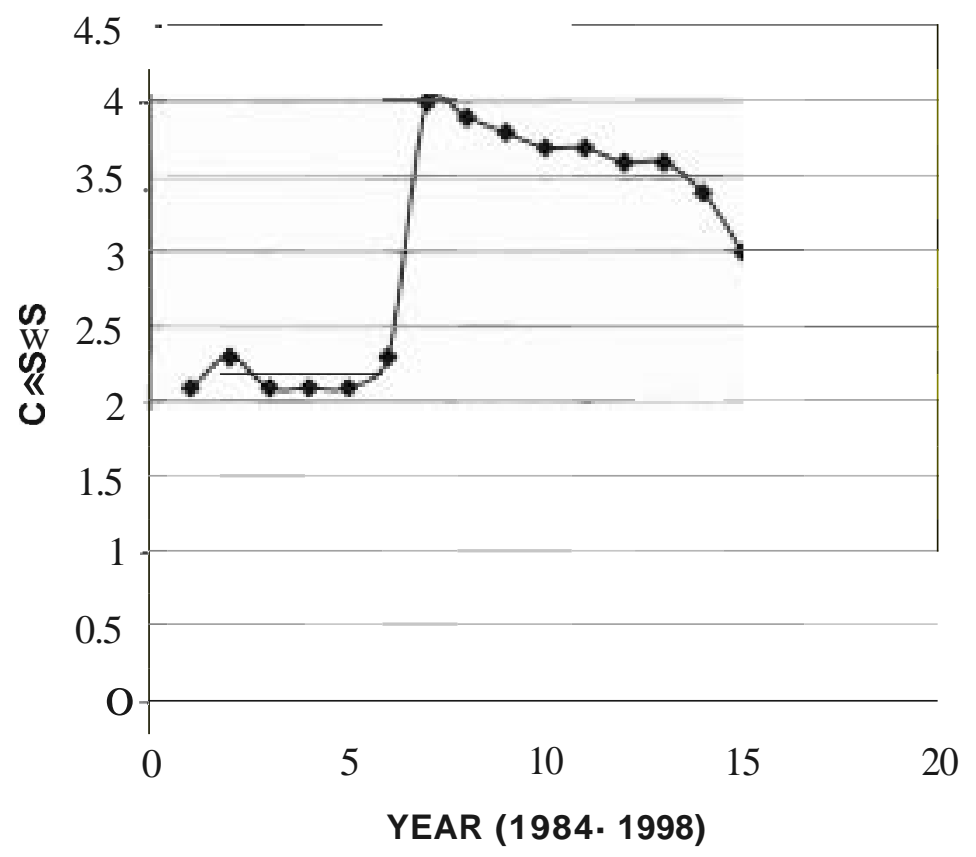

Figure 2. Injury and Illness Cases per 200,000 Hours vs. Time 
pursuit of continuous improvement in the lessening of risk, we identify and enhance methods that are currently used at DOE sites and introduce the relatively new concept of worker-driven behavior-based methods to reduce risks.

It has been stated that DOE has made progress in the area of worker and conununity safety. Examples show that when acute problems and safety concerns are addressed as they arise, safety issues can be "solved." But this approach is not effective in keeping rates low in the long run. It involves going from problem to problem, often with little or no attempt to address the root cause. Although the goal is to make the workplace safer, as Figures I and 2 show, incidents occur entirely unexpectedly or problems reoccur.

Therefore, a method needs to be developed to predict the relative levels of risk to the worker as he/she is performing tasks in the workplace. The tasks could be at the facility, the program, or the site level. Such a level of prediction would allow identification of work areas that might require additional monitoring and/or control measures, additional training of personnel, or increased required surveillance. 


\subsection{Methods}

The methods used to reduce risks to workers must include the enhancement of existing ISM systems and the development of accurate and reliable performance indicators. The details of these methods and effectiveness in the reduction of worker risks are described below.

\subsection{Enhancement of ISM Systems}

Each of the areas discussed below can be directly connected to one of the core functions of ISM. Incorporation of behavior-based safety (BBS) principles assists in the performance of work - both in the short-term and long-term. Based on results seen in the field, a decrease in the number of accidents/incidents is often seen after these principles have started to be used. The development of relative hazard factors is included in the core function of identifying and analyzing the work hazards. These are also useful when comparing different tasks and making decisions on priorities (e.g., which specific safety hazards to be addressed first). The use of electronic standards based management systems is directly related to the development and implementation of controls within the ISM. The development and use of performance indicators falls under the core function of assessing the effectiveness of the ISM and the production of feedback of results to improve the process.

\subsubsection{Incorporation of Behavior-Based Safety Principles}

Behavior-based safety principles systematically promote behaviors that prevent injuries. Specific behavioral safety systems may vary in form and complexity but share several common elements: targeting behaviors that impact safety, defining the behaviors adequately to measure them reliably, developing and implementing methods for measuring the behaviors for tracking and establishing goals, providing feedback, and reinforcing progress (Sulzer-Azaroff and Austin 2000).

Results from safety walkthroughs and interviews with staff will quite often reveal the importance of getting the workers involved in the entire safety process. Years of research have produced methods to incorporate behavior-based principles into the workplace. In some situations, the current focus appears to be on looking at acute situations, using performance indicators to evaluate the current, or short-term, status of safety. Solutions are implemented to "fix" these items and do not look in detail at changing the overall behavior of the workers. Unless the behaviors and attitudes of the workers are changed, there is only so much a safety-improvement plan can do. One leading BBS expert, Dr. Thomas Krause, has described this situation as a "performance plateau" where even with continuing effort to improve safety, there is no continuous improvement seen (Krause 1995).

Krause notes that continuous improvement in a safety program can be seen when employee involvement is mixed with the proper use of behavior and statistical science. Two factors are keys for success: (1) scientific measurement and management of all employee levels of workplace behavior, and (2) the involvement of all employees in this ongoing feedback and problem-solving process. Common management errors include the following: 
- focusing measurement exclusively on the end point of the process - The result looks only at the metrics (e.g., accident frequency rate).

- blaming the employee for accidents

- going for short-term results and not looking for long-term solutions.

If a safety management system appears to have entered into a "performance plateau" and improvements in the system are required, changes can be made. However, the effects of those changes need to be tracked and evaluated in order to know when or if changes in safety are occurring because of the fixes that are being implemented. The performance outcomes of some safety metric measures can be so far "downstream" that they are unsuited for proactive monthly, or even quarterly, performance management. Indeed, the greater the emphasis on incident frequency rate, for instance, the more unreliable the metrics can become. People learn how to "make the numbers come out right." Then, the rewards or punishments meted out because of the metrics can be seen by staff as meaningless. Reporting problems (e.g., with first aid, recordable, lost-time injuries) and classification problems (e.g., making accidents look less severe than they really are) exist with the traditional safety measurement methods. Incentive programs often contribute to the abuses of the system. Krause (1995) and others (see, e.g., Sulzer-Azaroff and Austin 2000) have suggested that incentive programs should be eliminated.

Instead, Krause suggests using statistical techniques with the incident data. The first step is to choose relevant variables that are meaningful. These depend on the situation of the workplace, e.g., the number of workers, the total number of hours worked, the stability in both of these numbers, and other data specific to the situation desired to be evaluated. It is important to understand what the statistical calculations represent and where there could be faulty assumptions in the data. Control charts that show accident rate versus time can be created for trending analysis. However, one needs to remember that it is very easy to misinterpret data to attribute causes to a random occurrence. One should be looking for consistent summary data that represents a significant change. There are a number of factors that can influence the incident data (Krause 1995):

- changes in exposure

- quantity of work being done

- type of work being done

- new employees

- changes in equipment or process

- atmosphere or quality of work life

- changes in leadership

- changes in labor relations

- changes in production pressure

- conflict and stress

- weather. 
One method to incorporate the input from the workers into the safety management system that has not been routinely used is the use of peer-to-peer observation during actual performance of work. The observers need to be selected carefully and must be trained in the proper techniques and know the job well that they are observing. The results will assist in the continuous improvement that is being sought. This can be a key in the changing of the worker "culture" and can change an entire safety measurement and control process.

The behavior-based approach to safety focuses on observable and measurable actions that are considered critical to safety at a particular facility or within a program. It is a very task-oriented view of behavior. The behaviors are important, no matter what the workers' attitudes are. Behavior-based does not mean focusing on personal issues, which would not be an effective way to achieve continuous improvement. Krause notes that "in a well-functioning safety process (not program) individuals do increasingly feel responsible for safety - but their feelings are the result, not the cause, of an effective behavior-based safety initiative" (Krause 1995). What results from programs that have been used in the past (e.g., incentive programs, motivational programs, punitive processes) are very often only a temporary fix to the problem. Resistance from personnel can often be created, often from negative attention directed at one person or because of someone who is passed over for a positive citation. Focusing on persons can actually create indifference or cynicism. The behavior-based approach supports focusing on the one thing that people who are properly fit for their jobs can directly control: their task-related actions. Allowing the worker to have input in order to control his or her area of work is the key to improving safety.

Dave Fox, of the Idaho National Engineering and Environmental Laboratory (INEEL), lists the following attributes as key to successful implementation (Fox 2000):

- integrating the Voluntary Protection Program (VPP) (DOE 2000b) and ISM initiatives to enhance worker involvement

- building a positive working relationship between workers and first-line management

- building a "questioning attitude" in the work force

- tailoring training appropriate to the craft, and

- minimizing paperwork.

In a paper entitled "Does BBS Work? Behavior-Based Safety \& Injury Reduction: A Survey of the Evidence," Beth Sulzer-Azaroff and John Austin conclude that the 33 studies that they evaluate suggest that, despite some reservations about how accurately the published literature reflects reality, incidence rates have been reported to decline following implementation of BBS systems (Sulzer-Azaroff and Austin 2000). The interest in this approach appears to be growing and may be justified by the gains many companies have reportedly achieved. 


\subsubsection{Development of Relative Risk Factors}

Different tasks have different hazards or risks associated with performing them. The risk to perform a job may be high because the potential consequence of an accident is high or because the probability of an accident is high. Routine tasks are normally associated with low risks: the hazards associated with the job are usually very well known, controls are in place, and the probability of an accident occurring is usually low because people perform the tasks on a frequent basis. Within a specific project, there could be hundreds of tasks to perform that have safety issues associated with them. More than likely, however, many fewer jobs involve medium to high risk levels. In order to evaluate the overall risk associated with a project, the separate project tasks need to be evaluated. The same process must be used when comparing programs to programs, facilities to facilities, etc. The question of relative risks or hazards comes up quite often.

One method that can be used to determine relative risk factors is the evaluation of detailed tasks, which normally focuses on mid- to higher-level tasks effecting the majority of personnel within a project, program, or facility. However, the evaluation can easily get bogged down in details and lose track of the level necessary to make good risk or hazard decisions. Job hazard analyses (JHAs) are usually prepared for jobs before they are authorized. The hazards of performing a task have to be identified along with the probability of an accident occurring. The risks for several different jobs within projects can be "summed" to come up with relative risk factors when comparing jobs. In fact, all of the risk factors associated with the jobs need to be considered in order to evaluate and compare projects, programs, or facilities. The overall risk of the larger "unit" consists of the contributions of all of its subparts. Data are obtained regarding the number of personnel performing the "most-hazardous" or "high-risk" jobs within a project or program. Then, project or program risks for different projects, programs, and facilities can be estimated. Comparisons can be made to other projects, programs, and/or facilities when appropriate.

One way to express the summation of these relative risks would be:

$$
\mathrm{R}_{\mathrm{T}}=\sum_{\mathrm{i}} \mathrm{P}_{\mathrm{i}} \times \mathrm{S}_{\mathrm{i}}
$$

where $R_{T} \quad$ total risk

$\mathrm{Pi} \quad$ probability of an incident happening while performing a specific task

Sj potential severity of a specific incident.

\subsubsection{Use of Electronic Standards-Based Management Systems}

Conventional paper and electronic approaches to SBMS provide staff with facility-wide standards, procedures, and guidelines that are current, accurate, and relevant to the work they perform. SBMSs deliver enhanced safety standards including risk-based standards. The trend toward the use of electronic SBMSs will reduce the resource and expertise barrier to completing and using results of risk analyses in ISM. For example, techniques, data, and project baselines could be located on a central SBMS website. 
Much of the information involved (e.g., material safety data sheets, safety procedures, sampling techniques, etc.) could be standardized and made available to all interested workers.

The increased accessibility of hazard, control, and risk information is directly related to reduced accident rates. Staff will have faster access to the correct information they need to do their jobs. It must be assumed that the workers use information that is made available. The SBMS contributes to a more requirement-compliant organization by making sure that up-to-date regulations are used. Workers can perform their jobs knowing that if they follow the procedures, they will not only be in compliance with the regulations, they will be using procedures reviewed by the appropriate subject matter experts.

\subsubsection{Use of Performance Indicators}

PerfOlmance indicators have been designed and established to track different safety metrics through the life of a program, project, facility, etc. However, they can be difficult to interpret. Moreover, they have strengths and weakness (discussed below). The ability to look at an extremely short-term snapshot of the safety picture should be considered for use under precautionary circumstances. Over-reaction to an apparent negative result for a performance indicator can do more harm than good. Long-term trending results are much better guides on which to make decisions.

Weaknesses of statistical data should not discourage their use in risk assessment. We need to recognize their weaknesses, however, and use that knowledge in prudent interpretation of the data. Statistical techniques that can be used with incident data have been established. The first step is to choose relevant variables that are meaningful. These depend on the situation of the workplace - the number of workers, the total number of hours worked, the stability in both of these, and other factors specific to the situation being evaluated. It is important to understand what the statistical calculations represent and where there might be faulty assumptions in the data. Control charts that show accident rate versus time can be created for trending analysis. One should be looking for consistent summary data that represents a significant change.

\subsection{Performance Indicators}

The CAIRS database and systems like it have been used for a number of years. An early form of the CAIRS was first used in 1979 and other statistical methods and metrics have been used by Occupational Safety and Health Administration (OSHA) and the Bureau of Labor. These systems are well-established and can be useful in keeping track of current incident rates and trends. However, the CAIRS system and outputs need to be better understood at DOE sites and the data entered into the database better controlled. The types of accidents that are included in the database as well as the interpretation of what constitute types of incidences have to be standardized so that comparisons can be made site to site, contractor to contractor, and year to year. Eliminating workers' fear of punishment for reporting an accident or incident could greatly enhance CAIRS data. Elimination of incentive programs (i.e., giving gifts/prizes for good safety records) would also help to improve the reporting system. 
There are hundreds of other metrics that can be calculated and followed over specific time intervals in order to determine if the workplace is getting safer or not. Some that are routinely followed may be calculated from the raw data in CAIRS or from other data obtained from site records:

- OSHA recordable case rate

- occurrence report corrective actions

- collective dose

- reportable skin and personal clothing contamination

- number and magnitude of unplanned radiological events

- number of employee safety concerns

- total number of occurrence reports

- fire protection device test failures.

It is very easy to get lost in the numbers and the statistics of the numerous performance indicators available. Several groups, including the DOE Safety Management Implementation Team (SMIT), the Energy Facility Contractor's Group (EFCOG) ISM Working Group, and the Institute of Nuclear Power Operations (INPO), are currently attempting to identify leading indicators. Leading indicators would be ones that have proven to be representative and accurate of the workplace safety situations.

As discussed earlier, there are strengths and weaknesses in using a statistical system such as CAIRS. The strengths include the following:

- Data from all DOE sites are available.

- Relative hazard weighting factors are "standardized" (e.g., reference-able).

- Comparisons among sites can be made.

- Comparisons can be made among projects, programs, and facilities on a single site or among sites.

The weaknesses of CAIRS and other similar accident databases include the following:

- Near misses are not recorded.

- The system does not grade within severity of injuries.

- The system ignores proactive steps.

- The focus is on acute accident situations, not chronic illnesses.

- Record-keeping rules may not be consistent across the DOE Complex. 
- Not all accidents are reported, so some data are left out of the database.

- It is nearly impossible to separate out EM-related work or work type, e.g., construction only. Because CAIRS is for the most part focused on individual contractors, many categories of interest may be blurred.

\subsubsection{Relative Risk Comparison for Worker Injury/IIlness}

The approach to assessing the relative risk from injuries or illnesses (non-radiological) associated with working on a DOE project uses the concept of Relative Physical Hazard Level (RPHL). Basic information has been obtained from the DOE CAIRS database. The data in the CAIRS database is based on the actual experience of DOE facilities. Use of these data from CAIRS represents a statistical approach to worker risk estimation that is based on experience. RPHL is very similar to the "cost index" now reported by DOE sites. The same weighting factors are used; however, the emphasis is not placed on the "cost" of accidents in dollars.

The RPHL is calculated using the following formula (Briscoe 1988):

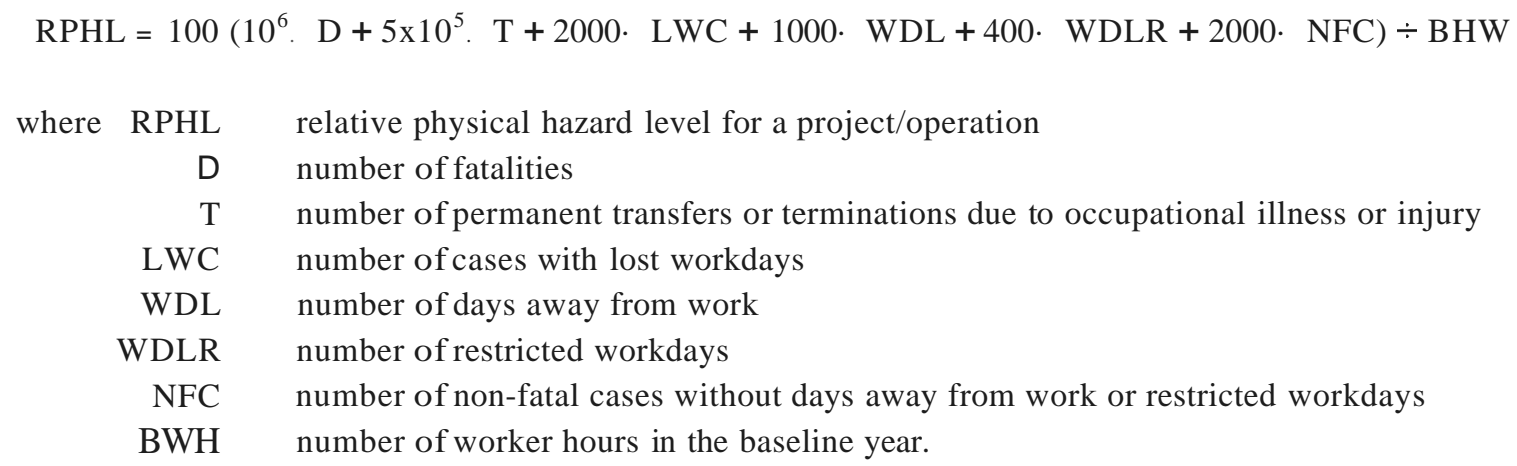

The RPHL can be thought of as the relative risk per 100 hours worked of all occupational injuries and illnesses. It can be calculated for any organizational component (DOE site, or major site program) and for a range of time periods (month, quarter, year). CAIRS compiles quarterly and annual data from hundreds of organizational units, going back to 1980. Since the RPHL is a rate (per unit of worker hour), levels for a given organizational unit can be compared for various time periods and thus be used for a trending tool. RPHLs for various organizations for various types of work or for specific projects or tasks can be compared to give a measure of relative risk.

The advantages of using the RPHL as an indicator of worker risk include the following:

- an accepted methodology used across the DOE complex

- data based on actual experience

- accessibility - available on a DOE website. 
In order to interpret the RPHL, one requires knowledge of the control measures that are in place, any restrictions placed on entering data into CAIRS (e.g., different interpretations of guidelines), and any other infonnation that may make the work perfonnance situation unusual. 


\subsection{Results}

Using an example site from the CAIRS database, the RPHL can be calculated for the site and for site production. With the RPHL for site program operations and data projecting future worker hours, a relative physical hazard index can be calculated to gauge relative future risks.

\subsection{Calculation of Relative Physical Hazard Levels}

CAIRS RPHL data are available for an entire DOE Site (all entries under the specific DOE Operations Office) and for a specific Operation Type on that site. For our example case, we will use the operation type "Production," which is a superset of the Site Program used in this example. Data were extracted from the CAIRS database for the Example Site and the Example Site Production from 1993 through the 1998. The data are presented in Table I.

Table 1. Example Relative Physical Hazard Levels

\begin{tabular}{|c|c|c|}
\hline Year & $\begin{array}{c}\text { Example Site } \\
\text { RPHL }\end{array}$ & $\begin{array}{c}\text { Example Site } \\
\text { Production } \\
\text { RPHL }\end{array}$ \\
\hline 1993 & 71.90 & 64.43 \\
\hline 1994 & 33.48 & 21.98 \\
\hline 1995 & 31.24 & 15.54 \\
\hline 1996 & 17.48 & 11.40 \\
\hline 1997 & 12.60 & 8.62 \\
\hline 1998 & 7.63 & 6.04 \\
\hline
\end{tabular}

To demonstrate the applicability of this methodology to a major site program, a specific site program was chosen. This program is a moderately funded program (say, 10-20\% of total site funding) that has specific milestones and budgets associated with it. The mission is well-established and has projected work for the next 20+ years. Most of the work is performed at one facility onsite and the facility activities are covered under the CAIRS database for Production entries, as tabulated in Table I. The site program evaluated has a majority of the staff working for one contractor; but that contractor has several different organizations.

CAIRS could be used to determine an RPHL for the Example Site Program by performing a database query on the Example Site Production entries. Approximately a dozen entries per quarter are found by this query, and each entry has the location and organization number of the incident. Each entry also displays the values needed in the RPHL calculation, such as the number of days away from work and number of restricted workdays. All values needed for an RPHL calculation can be obtained from this query except for the number of worker hours. We were able to obtain the number of worker hours by contacting the person named in the CAIRS records (a site-contractor employee) and that person was able to provide these numbers. Table 2 presents the values for the Example Site Program for 1997 and 1998. 
Table 2. Relative Physical Hazard Level (RPHL) for the Example Site Program Operations

\begin{tabular}{|c|c|c|c|c|c|c|c|c|c|c|c|c|c|c|c|c|}
\hline \multicolumn{2}{|l|}{ Organization } & Year & $Q$ & $\begin{array}{c}\text { Worker } \\
\text { Hours }\end{array}$ & TRC & $\begin{array}{l}\text { TRC } \\
\text { Rate }\end{array}$ & LWC & $\begin{array}{c}\text { LWC } \\
\text { Rate }\end{array}$ & WDL & WDLR & LWD & $\begin{array}{c}\text { LWD } \\
\text { Rate }\end{array}$ & NFC & Deaths & $T I T$ & RPHL \\
\hline \multicolumn{2}{|l|}{ Facility Only } & 1997 & 1 & 207,412 & 4 & 3.9 & 1 & 1.0 & 0 & 12 & 12 & 11.6 & 3 & 0 & 0 & 6.17 \\
\hline \multicolumn{2}{|l|}{ Facility Only } & 1997 & 2 & 209,350 & 2 & 1.9 & 2 & 1.9 & 0 & 81 & 81 & 77.4 & 0 & 0 & 0 & 17.39 \\
\hline \multicolumn{2}{|l|}{ Facility Only } & 1997 & 3 & 221,224 & 2 & 1.8 & 0 & 0.0 & 0 & 0 & 0 & 0.0 & 2 & 0 & 0 & 1.81 \\
\hline \multicolumn{2}{|l|}{ Facility Only } & 1997 & 4 & 171,940 & 1 & 1.2 & I & 1.2 & 8 & 7 & 15 & 17.4 & 0 & 0 & 0 & 7.44 \\
\hline \multicolumn{2}{|l|}{ Year's Total } & 1997 & & 809,926 & 9 & 2.2 & 4 & 1.0 & 8 & 100 & 108 & 26.7 & 5 & 0 & 0 & 8.15 \\
\hline \multicolumn{2}{|l|}{ Facility Only } & 1998 & 1 & 211,611 & 5 & 4.7 & 0 & 0.0 & 0 & 0 & 0 & 0.0 & 5 & 0 & 0 & 4.73 \\
\hline \multicolumn{2}{|l|}{ Facility Only } & 1998 & 2 & 200,980 & 3 & 3.0 & I & 1.0 & 3 & 36 & 39 & 38.8 & 2 & 0 & 0 & 11.64 \\
\hline \multicolumn{2}{|l|}{ Facility Only } & 1998 & 3 & 209,952 & 0 & 0.0 & 0 & 0.0 & 0 & 0 & 0 & 0.0 & 0 & 0 & 0 & 0.00 \\
\hline \multicolumn{2}{|l|}{ Facility Only } & 1998 & 4 & 173,644 & 6 & 6.9 & 1 & 1.2 & 0 & 48 & 48 & 55.3 & 5 & & & 17.97 \\
\hline \multicolumn{2}{|l|}{ Year's Total } & 1998 & & 796,187 & 14 & 3.5 & 2 & 0.5 & 3 & 84 & 87 & 21.9 & 12 & 0 & 0 & 8.11 \\
\hline \multicolumn{17}{|c|}{ DAFWC: $\quad$ Cases with Days Away from Work } \\
\hline \multicolumn{17}{|c|}{ LWC: $\quad$ Number of Cases with Lost Workdays } \\
\hline \multicolumn{17}{|c|}{ LWC Rate: LWC per 200,000 Worker-Hours } \\
\hline \multirow{2}{*}{$\begin{array}{l}\text { LWD: } \\
\text { LWD Rate: }\end{array}$} & Nur & mber of & Lost & Workdays & & & & & & & & & & & & \\
\hline & $\mathrm{LW}$ & D per 2 & 00,0 & 0 Worker- & Hours & & & & & & & & & & & \\
\hline \multicolumn{2}{|l|}{ NFC: } & mber of & Non & Fatal cases & withou & Lost & Vorkday & & & & & & & & & \\
\hline \multicolumn{2}{|r|}{ Q } & arter & & & & & & & & & & & & & & \\
\hline \multicolumn{2}{|l|}{$T I T:$} & mber of & Ten & inations or & Transf & rs due & to Injury & or Illnes & & & & & & & & \\
\hline \multirow{2}{*}{$\begin{array}{l}\text { TRC: } \\
\text { TRC Rate: }\end{array}$} & Tot & al Reco & $\mathrm{rdab}$ & e Cases & & & & & & & & & & & & \\
\hline & $\mathrm{TR}$ & C per 2 & 0,00 & 0 Worker-H & ours & & & & & & & & & & & \\
\hline WDL: & Nur & nber of & Wor & xdays Lost & & & & & & & & & & & & \\
\hline WDLR: & Nur & mber of & Wor & K Days Los & est & $(0$ & he job & but at & nother $\mathrm{c}$ & uty, or $<\mathrm{f}$ & ull-time, & or not a & le to $p$ & form all & uties) & \\
\hline
\end{tabular}


The RPHL for the Example Site Program could be calculated for only 2 years because worker-hour data specific to the program was not available for time periods before 1997. This unavailability seems to result from a change in contractors operating the facility, which made previous data difficult to obtain. Some interesting features can be seen in Table 2. The RPHL varies dramatically from quarter to quarter in each year, but the averages of the four quarters for each of the two years shown are nearly identical. The average annual RPHLs for the Example Site Program (8.15 for 1997 and 8.11 for 1998) compare well to the Example Site Production RPHLs for the same years (8.62 and 6.04, but note that the 1998 Site Production RPHL includes only calendar quarters 1-3, while the Example Site Program data covers all four quarters).

The quarter-to-quarter fluctuation can be explained by a statistical uncertainty produced by a small number of random events. The number of total recordable cases (TRC) ranged from 0 to 6 for each of the eight quarters shown in Table 2. This represents a small amount of data to use as the basis for a long-tenn trend. The annual totals still involve a small number of incidents: 9 in 1997 and 14 in 1998. Again, this small amount of data would seem to indicate a high uncertainty, but the annual RPHLs for the 2 years were remarkably close to each other. The good agreement for these years would indicate that an RPHL of 8.1 should be a reasonable tool for trending into the future.

\subsection{Calculation of Predicted Levels of Relative Risks (RPHI) versus Time}

Worker risk for a major program can be estimated for future work by applying a representative RPHL to an activity level projected for the future time-frame. However, there are potential problems with this strategy:

- The future work may involve activities that are not well-represented by the current RPHL.

- Improvements in work practices could result in a safer workplace, with activities that would be better represented by a lower RPHL than that used.

A more accurate approach would be to group the work activities into subgroups with similar worker risks, e.g., office workers and managers, craft services, radiation monitors, and health physicists.

Representative RPHL values could be derived for each, and the FTEs for each worker subgroup would be estimated for each year in the future time-frame. Then, the subgroup RPHL could be multiplied by the subgroup FTE to obtain an overall subgroup risk, and the subgroup risks could be summed for each year. This would give a year-by-year projection of future risk, based on a more detailed projection of the type of work involved. Two problems would prevent this approach from working: the difficulty in detennining representative RPHL values for worker subgroups, and the difficulty of finding program projections that break down the future work to this level of detail.

Assuming that the RPHL of 8.1 is applicable to future work activities in the Example Site Program, future worker risk for the program can be determined by applying this RPHL value to the projected annual labor requirements for the Example Site Program in future years. A substantial amount of 
information is readily available on the future of major DOE Site programs because it is necessary to make this information easily accessible to a variety of stakeholders, including State agencies and Native American Tribes.

Direct FTE projections can be available from site or program scheduling/planning personnel. Projected worker hours for each year for the Example Site Program are listed in Table 3.

Table 3. Annual Relative Physical Hazard Indices

\begin{tabular}{|c|c|c|}
\hline FY & Worker Hours & RPHI \\
\hline 1999 & 800,000 & 64,800 \\
\hline 2000 & $1,088,181$ & 88,143 \\
\hline 2001 & 933,468 & 75,611 \\
\hline 2002 & 837,830 & 67,864 \\
\hline 2003 & 902,032 & 73,065 \\
\hline 2004 & 921,146 & 74,613 \\
\hline 2005 & $1,018,952$ & 82,535 \\
\hline 2006 & 764,929 & 61,959 \\
\hline 2007 & 769,386 & 62,320 \\
\hline 2008 & 639,365 & 51,789 \\
\hline 2009 & 628,527 & 50,911 \\
\hline 2010 & 596,702 & 48,333 \\
\hline 2011 & 610,531 & 49,453 \\
\hline 2012 & 541,908 & 43,895 \\
\hline 2013 & 492,636 & 39,904 \\
\hline 2014 & 478,999 & 38,799 \\
\hline 2015 & 314,797 & 25,499 \\
\hline
\end{tabular}

The RPHL can be combined with the number of worker hours to determine a relative physical hazard index (RPHI), which is calculated by:

$$
\mathrm{RPHI}=\mathrm{RPHL} \cdot \mathrm{AWH} / 100,
$$

where RPHI relative physical hazard index

RPHL relative physical hazard level

AWH projected worker-hours for each year.

The value of 100 was put in the denominator to remove the factor of 100 included in the original equation defining RPHL and to make the scale of the numbers more manageable. Relative physical hazard indexes are tabulated in Table 3.

The RPHI is a unitless factor. It indicates relative risks from year to year. A graph of RPm as a function of time is given in Figure 3. 


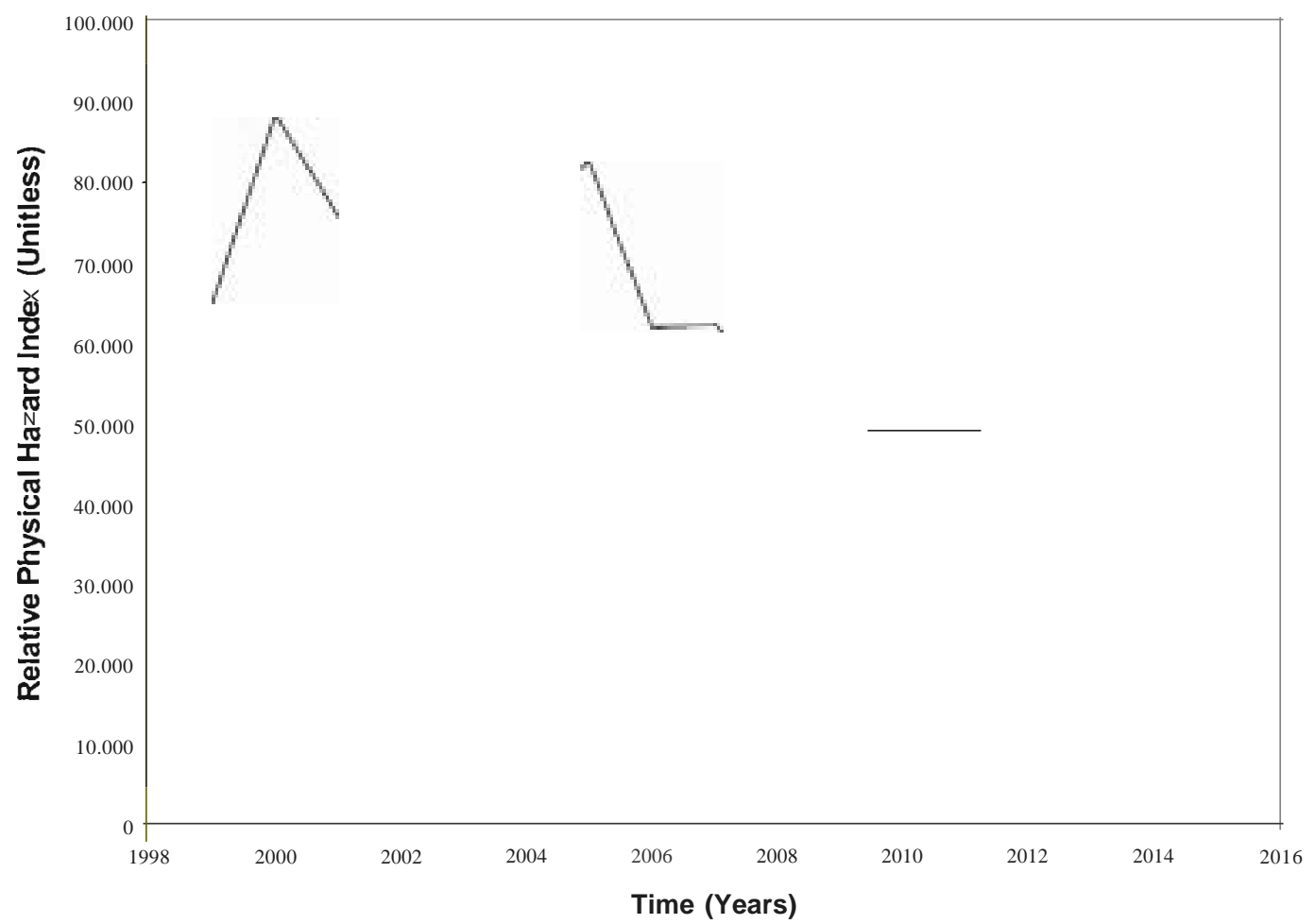

Figure 3. Relative Physical Hazard Index as a Function of Time - Simple Model-Based on Projected Labor Hours

This simple model incorporates the statistical data obtained from CAIRS for a sample site facility normalized for the number of labor hours for a specific time period. Further adjustments in the model would be based on specific information obtained from the site and/or facility. Parameters of importance include:

- types of tasks and associated risk factors

- types of workers, their experience levels, their training records, their past safety records

- effects ofISM system improvements (e.g., use of electronic SBMS, implementation of BBS processes)

- level of VPP status.

All of these all would have an impact on the risk levels associated with the work being performed. 


\subsection{Conclusions}

An evaluation of the current safety conditions and environment in the DOE workplace shows a situation that has improved over the last few years but can still be better. Some of the safety performance indicators appear to be getting better as acute safety issues are addressed. Long-term, continuous improvement has been seen at some DOE sites and warrants the use of some of the principles addressed in this paper more thoroughly throughout the complex.

It is recognized that some of the methods discussed in this report on the evaluation of workplace safety levels or the reduction of risks in the workplace do not apply to lower-risk work environments. They are more applicable to high-risk tasks, projects, or programs.

It is clear that DOE and DOE-contractor management supports safety. At any DOE site, including local DOE field offices and management of the site contractors, there is physical evidence that safety is taken seriously. This evidence includes safety signs, posting of hazards and hazard levels, requirements for personal protective equipment, and access controls. Pre-job safety meetings are held and documented. Training is provided in how to do tasks correctly and safely. Procedures are written with safety in mind, and safety staff review them before procedures are authorized for use. Worker involvement is discussed, and it is agreed that for a better team, for more "buy-in" to the safety culture, workers must be involved in the design, maintenance, and operation of equipment and procedures used in the workplace. In the ISM systems being established and improved throughout the DOE complex, workers are actively involved in several aspects.

Some of the aspects of the current safety management systems are working well and should not be changed. Other aspects need to be kept but improved or enhanced. Others yet just need more time to "mature" - for workers to "buy-in" to the system, especially after a drastic change. Even the safety metrics discussed here have positive attributes, despite their well-recognized weaknesses. DOE is beginning to take more advantage of behavior-based safety principles that have been developed to move the level of safety to the "next step."

One of the ISM measurement tools used on all DOE sites that can be employed in a more productive and useful manner is the use of performance indicators to track the level of relative risks on the sites. Other leading performance indicators are being established. The interpretation and understanding of the parameters being measured are critical to its success. Both strengths and weaknesses have been identified and discussed in detail. It has been shown that performance indicators can be used to follow individual tasks, projects, programs, and work within a facility. Comparisons among sites can also be made. It has also been shown that the simple model developed in this paper can be used in a predictive mode to estimate the risk to workers, as future tasks are being planned and scheduled. In the development of a more complex model, parameters such as the types of work being performed and associated risk factors; types of workers, their training and experience levels, their past safety records; and ISM system improvements would need to be considered. 


\subsection{References}

Briscoe, G. J. 1998. "Cost of Injury Study." System Safety Development Center, EG\&G Idaho, Inc., Idaho Falls, Idaho.

Fox, D. 2000. "Worker Perspectives on ISM - Worker Involvement in the ISM Process." Presentation given at the Waste Management 2000 Conference, February 27- March 2, 2000, Tucson, Arizona.

Krause, T. R. 1995. Employee-Driven Systemsfor Safe Behavior. New York: Van Nostrand Reinhold.

Krause, T. R., J. H. Hidley, and S. J. Hodson. 1990. The Behavior-Based Safety Process. New York: Van Nostrand.

Richardson, B. 2000. "Memorandum To All Department And Contractor Employees: SafetyAccountability and Perfonnance." DOE, Washington, D.C. Accessed at http://tis.eh.doe.gov/portal/memo030899.htm, September 8, 2000.

Sulzer-Azaroff, B., and 1. Austin. 2000. Does BBS Work? Behavior-Based Safety and Injury Reduction: A Survey ofthe Evidence. Professional Safety, American Society of Safety Engineers, Des Plaines, Illinois.

U.S. Department of Energy (DOE). 2000a. "Achieving ISM at the Task Level Complex-wide Enhanced Work Planning Successes." DOE, Washington, D.C. Accessed at http://tis.eh.doe.gov/ewp/success.htm, September 8, 2000.

U.S. Department of Energy (DOE). 2000b. "Department of Energy Voluntary Protection Program." DOE, Washington, D.C. Accessed at http://tis.eh.doe.govNpp/GI/gi.htm, September 8, 2000.

U.S. Department of Energy (DOE). 1997. DOE Order 5480.23, Nuclear Safety Analysis Report. DOE, Washington, D.C.

Worker Risk Workshop Report. 1997. Worker Risk Workshop Report. Workshop on Worker Health and Safety, San Antonio, TX, April 1-3, 1997. 